Research Paper:

\title{
The Effect of Spiritual Training on the Moral Sensitivity of Nursing Students
}

\author{
Fatemeh Ekramifar $^{1} \odot$, Marhamat Farahaninia $^{2^{\star}} \odot$, Marjan Mardani Hamooleh $^{1} \odot$, Hamid Haghani $^{1} \odot$ \\ 1. Department of Community Health Nursing, School of Nursing and Midwifery, Iran University of Medical Sciences, Tehran, Iran \\ 2. Department of Psychiatric Nursing, School of Nursing and Midwifery, Iran University of Medical Sciences, Tehran, Iran. \\ 3. Department of Biostatistics, School of Public Health, Iran University of Medical Sciences, Tehran, Iran.
}

\begin{tabular}{|c|c|}
\hline $\begin{array}{c}\text { Use vour device to scan } \\
\text { and read the article online }\end{array}$ & $\begin{array}{l}\text { Citation Farahaninia, M., et al., 2018. The Effect of Spiritual Training on the Moral Sensitivity of Nursing Students. Journal } \\
\text { of Client-Centered Nursing Care, 4(4), pp. 213-222. https://doi.org/10.32598/jccnc.4.4.213 }\end{array}$ \\
dof'https://doi.org/10.32598/jccnc.4.4.213
\end{tabular}

(a) 0

Article info:

Received: 13 Apr 2018

Accepted: 02 Sep 2018

Published: 01 Nov 2018

Keywords:

Spirituality, Teaching,

Moral sensitivity,

Nursing students

\begin{abstract}
A B S T RA C T
Background: The main goal of nursing profession is to provide people's health that cannot be achieved only through the use of scientific methods, and it is essential to pay special attention to spirituality and ethics for its attainment. The current study aimed at determining the effect of spirituality training on the moral sensitivity of nursing students.

Methods: The current quasi-experimental study was conducted on 70 nursing students of the fourth and higher semesters (35 in each group) from Iran University of Medical Sciences selected by stratified sampling proportion to size method. Pre-test was administered to both groups; then the intervention group attended six training sessions, once a week each for one hour, and the post-test was administered to the two groups one month after the end of the intervention. Data were collected by demographic characteristics and the Korean Version of the Moral Sensitivity Questionnaire (K-MSQ), and analyzed by descriptive statistics including frequency distribution, mean and standard d deviation, and inferential statistics including Chi-square, Fisher test, t-test, paired t-test and analysis of covariance using SPSS V. 22.
\end{abstract}

Results: The study results showed a significant difference between the moral sensitivity score of the intervention group before $(4.07 \pm 0.53)$ and after $(6.36 \pm 0.18)$ training $(\mathrm{P}<0.001)$.

Conclusion: The obtained results indicated that the moral sensitivity score of nursing students increased after spirituality training. Due to the fact that nursing students are responsible for providing nursing services in their future careers, placing these concepts in their curriculum as a course unit or along with other courses, especially Islamic ethics and Islamic thought is recommended.

\section{* Corresponding Author:}

Marhamat Farahaninia, MSc.

Address: Department of Community Health Nursing, School of Nursing and Midwifery, Iran University of Medical Sciences, Tehran, Iran

Tel: +98 (912) 2059958

E-mail: mary_f2008@yahoo.ca 


\section{Highlights}

- The main objective of the nursing profession is to provide people's health through scientific methods, and observing ethical principles.

- The current study aimed to determine the effect of spirituality training on the moral sensitivity of nursing students.

- The obtained results indicated that the moral sensitivity score of nursing students increased after spirituality training.

- Because nursing students are responsible for providing care in their future careers, we recommend that these concepts, especially Islamic ethics and advice be included in their curriculum.

\section{Plain Language Summary}

The main goal of the nursing profession is to provide people's health by using scientific methods and observing ethical principles. The current study aimed at determining the effect of spirituality training on the moral sensitivity of nursing students. The intervention group attended six training sessions, once a week. The study data were collected by the Korean version of the Moral Sensitivity Questionnaire (K-MSQ). The obtained results indicated that the moral sensitivity score of nursing students increased after spirituality training. Because nursing students are responsible for providing patients' care in their future careers, including these concepts, especially Islamic ethical principles and advice in their curriculum is recommended.

\section{Background}

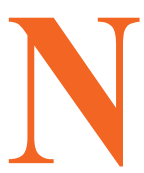

owadays, spirituality and ethics are discussed in response to stressful environments. Ethics can cause the spiritual growth of individuals (Baloochi Beydokhti et al. 2014). Different definitions of spirituality are proposed so far, since individuals choose different ways to achieve their goals of life. However, the concept of spirituality is similar for most people. Spirituality means faith and transcendence towards God, believing in a supreme being, and addressing the immaterial world; it is more general than religion. The concept of spirituality is close to religiosity, but it does not mean religiosity (Bolhari et al. 2013). People with a spiritual life are psychologically more healthy (Khodabakhshi et al. 2014).

Spirituality and ethics have a close relationship. Spiritual growth of people is achieved through ethics and in the light of morality. One cannot adhere to spirituality and trample morality at the same time (Galavandi 2016). Spirituality makes it possible for individuals to achieve a deeper understanding of their needs and thereby improve their spiritual well-being (Bolhari et al. 2013). Providing people with health as the main goal of nursing profession is achieved through the employment of scientific methods; but spirituality and ethics should be considered (Habibzade et al. 2010).
Nurses are the most effective service provider groups in the therapeutic system and their performance plays a huge role in improving the quality of health care. One of the effective factors for improving nurses' performance and increasing the quality of their care is observance of ethical standards (Hasanpour et al. 2012).

Moral sensitivity is sensitivity to ethical issues, and respect for patient's rights at the time of decision-making. Ethical sensitivity in nurses makes them use ethics better and more effectively in caring for clients (Abbaszadeh et al. 2010). Moral sensitivity is a combination of one's knowledge of dimensions of ethics and includes responsibility, giving importance to the issues, tolerance, and tranquility (Eizadi et al. 2013).

Considering that moral sensitivity is effective in choosing the appropriate ethical solution, improvement of moral sensitivity in taking care of the patients is of paramount importance (Nikjoo et al. 2014). Low moral sensitivity leads to making inappropriate decisions in the nursing profession. Therefore, further studies and training in this area are needed to increase the moral sensitivity.

Nursing students face contradictions in their workplace and should be sensitive to them. (Abbaszadeh et al. 2010). Moral sensitivity can be defined as the awareness of ethical values and paying attention to the existence of moral values in conflicting situations as well as individual self-awareness of the role and function under specific circumstances. Moral 
sensitivity helps the nurses to identify the right thing from the wrong one (Borhani et al. 2015). In their future career, nursing students are among the main members of healthcare team and should play an active role in protecting patients (Baykara et al. 2015).

Today, ethical issues are clearly visible in the work environment of health care; therefore nursing students need to be prepared to deal with such issues in their future roles. On the other hand, nursing students need to be prepared to face the challenges of their future roles (Tuvesson \& Lützén 2017). Higher moral sensitivity, among nurses, encourages them to make better clinical decisions, use ethical codes appropriately, and tolerate less stress (Kim et al. 2013). Ethical behavior also has positive effects on the quality of health care (Huang et al. 2016). However, lack of moral sensitivity can lead to negative health effects and violation of patients' rights (Lützén et al. 2010).

Moral sensitivity is the immediate perception of the vulnerable position of a patient and awareness of the meanings and ethical implications of decisions made on his part. Moral sensitivity is an important aspect of the ethical decisionmaking process. In conflicting situations in nursing, moral sensitivity has priority to awareness and understanding of one's responsibility (Tuvesson \& Lützén 2017). This kind of sensitivity is a cognitive ability that includes one's individual experiences, and the experiences of other people and all their value systems. Moral sensitivity as a product of one's life can undergo a change process on a continuous path (Baykara et al. 2015).

Moral sensitivity is a criterion of professional competence in nursing which is effective in the relationship among the nurse, the patient, and also the ethical performance. Various dimensions of this concept include the power of reasoning, scientific ability, and individual emotions; and attaining it, requires specific individual characteristics and educational readiness (Borhani et al. 2013).

Moral sensitivity is a prerequisite; a requisite and a necessary condition for nurses that enable them to make the best decisions for their patients, taking into account their expediency, attention, and interest at the same time (Huang et al. 2016). Nurses face situations that require a proper exposure to ethical issues in health care settings, therefore, the need to prepare nursing students to face ethical dilemmas in their future roles as nurses is severely felt.

Moral sensitivity is an important aspect of ethical decision-making process, but there is little awareness and recognition about the moral sensitivity of nursing stu- dents, and its progress and development can be achieved through nursing education (Tuvesson \& Lützén 2017).

The results of studies in the field of ethics show weaknesses in the ethical decision making of nurses (Baloochi Beydokhti et al. 2014) .In the real challenge of today's health environment, nursing students perceive conflicts between nursing ideals that are taught at the university and the profession they are supposed to enter (Tuvesson \& Lützén. 2017).

Ethics education in universities significantly increases students' awareness of the possible ethical conflicts that occur during clinical education, and can help students to recognize such conflicts (Macale et al. 2015). Given the fact that nursing students have low moral sensitivity (Tuvesson \& Lützén. 2017), doing studies that affect their moral sensitivity is of great importance. The current study aimed at determining the effect of spirituality training on the moral sensitivity of nursing students.

\section{Materials and Methods}

The current quasi-experimental study was conducted on nursing students of the fourth and higher semesters (since these groups of students were more familiar with the hospital environment and had gained more clinical experience than others). Exclusion criteria were unwillingness to continue the study or not attending one session of training.

After obtaining permission from the Ethics Committee on Research of Iran University of Medical Sciences (IUMS) and the approval of the research council, research was conducted in the Faculty of Nursing and Midwifery. By attending the students' classrooms, the researcher provided the students with the needed information such as the study objectives, duration, and explanations on the study conduction, that their participation was solely voluntarily and non-participation had no effect on their educational process, the use of information solely for the purpose of the present study, and providing the results to students after the study upon their request and putting the educational content at the disposal of the control group after completion of the study.

The students who agreed to participate in the study signed the informed consent. The sample consisted of 70 students (35 in each group) selected by proportion to size, stratified random sampling in different semesters. The required sample size was calculated at $95 \%$ confidence level and test power of $80 \%$, assuming that the effect of spirituality training on nursing students' moral sensitivity was at least $\mathrm{d}=8$, therefore, the effect of training was statistically significant. 
Table 1. Contents provided in the training sessions

\begin{tabular}{|c|c|}
\hline No. & Issues Provided in Each Session \\
\hline First session & Definition of the concepts of spirituality, religion and faith, the interweaving and differences of these concepts \\
\hline Second session & Characteristics of a spiritual person, the spiritual skills, the concept of spiritual well-being \\
\hline Third session & The place of spirituality in education and clinical work, spiritual care in nursing clinical practice \\
\hline Fourth session & $\begin{array}{l}\text { Self-awareness and its types including spiritual self-awareness, the importance of spirituality in self-awareness, } \\
\text { the relationship between self-awareness, spirituality and health }\end{array}$ \\
\hline Fifth session & $\begin{array}{l}\text { Relationship between spirituality and mental health, problem solving process, the problem solving steps with the } \\
\text { spiritual approach, the forgiveness and amnesty stages }\end{array}$ \\
\hline Sixth session & $\begin{array}{l}\text { Religious-spiritual confrontations, trust, faithfulness and forgiveness, patience, meditation and incantation, the } \\
\text { concept of generosity, its stages, consequences and also its growth }\end{array}$ \\
\hline
\end{tabular}

Client- Centered Nursing Care

Accordingly, the required sample size was estimated as $\mathrm{n}=32$ in each group and considering the $10 \%$ sample attrition, $\mathrm{n}=35$ students were considered.

Data were collected by a demographic form (including age, gender, marital status, educational semester, clinical experience and previous spiritual training) and the Korean version of Moral sensitivity Questionnaire (K-MSQ). K-MSQ was first developed by Lützén et al, in order to measure the moral sensitivity in Sweden and included 30 questions and six dimensions (Lützén et al. 1994). Its validity and reliability was assessed again in Korea in 2010 (K-MSQ) (Han et al. 2010).

To apply the questionnaire in Iran, the researchers concluded that three statements covers specifically the field of psychiatry, therefore, the questionnaire was reduced to 27 questions. K-MSQ has five dimensions, which measure nurses' moral sensitivity by a 7-point Likerttype scale, from 1 to 7 .

The total score is between one and seven, with the higher scores showing higher moral sensitivity, and given the fact that two questions are inversely scored, mean scores above four are identified as high moral sensitivity. The questionnaire assesses moral sensitivity in five dimensions including: 1. Patient-oriented care; 2 . Professional responsibility; 3 . Experiencing problems and ethical conflicts (conflict); 4. Applying ethical meanings to ethical decision-making (meaning); and 5. Benevolence. (Han et al. 2010).

It is noteworthy that Han et al. (2010) gave the authors permission to use the questionnaire. The validity of the Persian translated version of the questionnaire was assessed in Iran by content validity and its reliability was 0.81 using test re-test (Hasanpour et al. 2012). In the current study, the reliability of the questionnaire was calculated by the test re-test as (0.89).

\section{Procedure}

In the current study, pre-test and post-test were administered to both groups. In order to prevent information contamination, the study was first performed on the control group. After completing the informed consent, the researcher provided the questionnaire to the students in the control group. One month after the intervention period, the questionnaires were provided to them again. Then the process was repeated for the intervention group.

Training sessions began based on a booklet. Before intervention, the validity of the contents of the booklet was confirmed by the faculty members of the school of nursing. According to the scheduled timetable, six one-hour-sessions were held once a week using power point slides. The subjects were taught through lecturers and question and answer by the researcher under the supervision of a supervisor.

Due to the inability of all the subjects to attend the sessions together, two or three sessions were held every week on selected days, after coordination with the representatives of each group. Using books, articles and training packages approved by the Ministry of Health and Medical Education of Iran, a series of educational pamphlets, in 10-15 pages including headlines, summary notes and questions related to the sessions was given to the intervention group at the beginning of each session in accordance with the subject under discussion.

Attempts were made not to interfere with the classes of the students. Students were permitted to ask their questions in case of any ambiguity. The contents provided in each session are shown in Table 1 (Bolhari et al. 2013). The students were asked to participate in group discussions and practices, express their feelings and experiences, and also work and exercise outside the classroom. Finally, a summary of the topics presented at the meetings was provided to the students. One month after the 
end of the sessions, the questionnaires were completed in the intervention group. After the end of the study, the content discussed was given to the control group.

\section{Data analysis}

Analysis of the collected data was performed by descriptive statistics including frequency distribution tables, numerical indexes, and also inferential statistics including Chi-square, Fisher Exact test, t-test, Paired ttest, and analysis of covariance using SPSS V. 22.
Independent t-test was used to compare the moral sensitivity scores before and after intervention in the experimental and control groups and paired t-test was used to compare the moral sensitivity scores before and after intervention in each group $(\mathrm{P}<0 / 001)$

\section{Results}

There was no significant difference between the studied groups in terms of age $(\mathrm{P}=0.457)$, gender $(\mathrm{P}=0.806)$, and marital status $(\mathrm{P}>0.999)$. There was no history of passing a spirituality course before the study (Table 2 ).

Table 2. Demographic characteristics of the nursing students in intervention and control groups

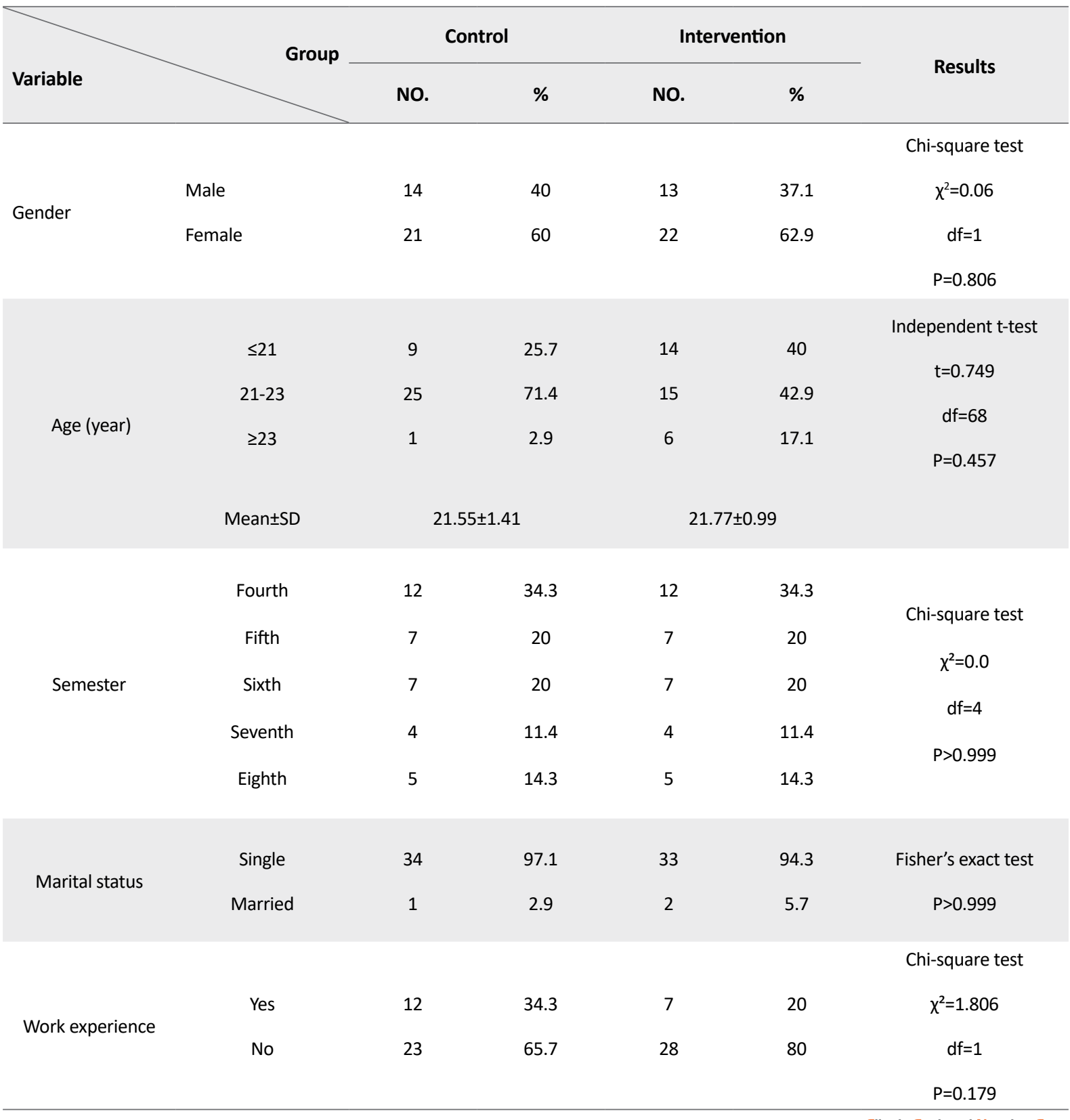


Table 3. Moral sensitivity and its dimensions in the intervention and control groups

\begin{tabular}{|c|c|c|c|c|}
\hline \multirow{2}{*}{$\begin{array}{l}\text { Moral Sensitivity } \\
\text { and its Dimensions }\end{array}$} & \multirow[t]{2}{*}{ Group } & \multicolumn{2}{|c|}{ Mean $\pm S D$} & \multirow{2}{*}{$\begin{array}{l}\text { Independent Sample T-test } \\
\text { Result }\end{array}$} \\
\hline & & Control & Intervention & \\
\hline \multirow{2}{*}{ Patient-oriented care } & Before & $4.37 \pm 0.86$ & $4.59 \pm 0.62$ & $t=-1.257 d f=68 \quad P=0.213$ \\
\hline & After & $4.31 \pm 0.72$ & $6.35 \pm 0.35$ & $t=-15.159 \mathrm{df}=68 \mathrm{P}<0.001$ \\
\hline Paired t-test result & & $t=-15.540 \mathrm{df}=34 P<0.001$ & $t=0.296 d f=34 P=0.769$ & \\
\hline \multirow{2}{*}{ Professional responsibility } & Before & $4.02 \pm 0.85$ & $4.36 \pm 0.66$ & $t=-1.838 d f=68 \quad P=0.070$ \\
\hline & After & $3.67 \pm 0.91$ & $6.49 \pm 0.43$ & $t=-16.584 d f=68 \quad P<0.001$ \\
\hline Paired t-test result & & $t=-14.243 d f=34 P<0.001$ & $t=1.603 \mathrm{df}=34 \mathrm{P}=0.118$ & \\
\hline \multirow{2}{*}{ Conflict } & Before & $3.42 \pm 0.82$ & $3.57 \pm 1.09$ & $t=-0.644 d f=68 P=0.522$ \\
\hline & After & $3.77 \pm 1.05$ & $6.26 \pm 0.46$ & $t=-12.785 \mathrm{df}=68 \mathrm{P}<0.001$ \\
\hline Paired t-test result & & $t=-12.377 \mathrm{df}=34 \mathrm{P}<0.001$ & $t=-1.599 \mathrm{df}=34 \quad P=0.128$ & \\
\hline \multirow{2}{*}{ Meaning } & Before & $3.93 \pm 0.88$ & $3.69 \pm 0.78$ & $t=1.203 \mathrm{df}=68 \mathrm{P}=0.233$ \\
\hline & After & $3.94 \pm 1.03$ & $6.26 \pm 0.41$ & $t=-14.722 d f=68 P<0.001$ \\
\hline Paired t-test result & & $t=-18.412 d f=34 P<0.001$ & $t=1.718 d f=34 P=0.095$ & \\
\hline \multirow{2}{*}{ Benevolence } & Before & $4.93 \pm 0.75$ & $4.89 \pm 0.86$ & $t=-0.644 d f=68 \quad P=0.522$ \\
\hline & After & $5.25 \pm 0.83$ & $6.36 \pm 0.37$ & $t=-12.785 d f=68 P<0.001$ \\
\hline Paired t-test result & & $t=-9.467 d f=34 P<0.001$ & $t=-1.597 d f=34 P=0.120$ & \\
\hline \multirow{2}{*}{$\begin{array}{l}\text { Moral sensitivity } \\
\text { (total) }\end{array}$} & Before & $4.13 \pm 0.60$ & $4.23 \pm 0.55$ & $t=-0.770 \mathrm{df}=68 \mathrm{P}=0.444$ \\
\hline & After & $4.07 \pm 0.53$ & $6.36 \pm 0.18$ & $t=-24.060 \mathrm{df}=68 \mathrm{P}<0.001$ \\
\hline Paired t-test result & & $t=-20.015 d f=34 \quad P<0.001$ & $t=0.383 \mathrm{df}=34 \mathrm{P}=0.704$ & \\
\hline
\end{tabular}

There were no differences between the mean score of moral sensitivity in the control $(4.13 \pm 0.60)$ and intervention $(4.23 \pm 0.55)$ groups $(\mathrm{P}=0.444)$ before the intervention. The differences between the mean scores of the students' moral sensitivity and its dimensions were not significant before and after the study in the control group (4.07 \pm 0.53$)(\mathrm{P}=0.704)$, but significant in the intervention group (6.36 \pm 0.18$)(\mathrm{P}<0.001)$.

There was a statistically significant difference in the mean of total moral sensitivity in the studied groups after intervention $(\mathrm{P}<0.001)$. The mean score of total moral sensitivity and its dimensions in the intervention group was higher than that of the control group. The mean scores of experiencing problems and ethical conflicts (conflict) dimensions in the intervention and control groups were less than that of all dimensions (3.57) before the intervention.
The highest score before (4.89) and after the intervention was related to the dimension of benevolence (6.36), and most of the changes were related to the dimensions of experiencing problems and moral conflicts (conflict), applying ethical meanings to ethical decision-making (meaning) and professional responsibility.

There was a statistically significant difference between the mean scores of moral sensitivity dimensions comparing the studied groups after the intervention, and also before and after the intervention in the experimental group. It was higher after the intervention $(\mathrm{P}<0.001)$ (Table 3$)$.

\section{Discussion}

The current study aimed at investigating the effect of spiritual training on the moral sensitivity of nursing 
students. The results showed no significant difference between the mean scores of moral sensitivity of the control and intervention groups before the intervention $(\mathrm{P}=0.444)$. The difference between the mean moral sensitivity score of the control group was not significant before and after the study, but it was significant in the intervention group $(\mathrm{P}<0.001)$.

No similar study was found in this area, and this section refers to the results of studies on moral sensitivity, including the study by Yeom et al (2017). The results of a study in Korea, entitled "the effect of ethics education on the moral sensitivity of nursing students" which was similar to the current study regarding the type of questionnaire used, showed no significant changes in the overall score of moral sensitivity before and after education.

But significant changes were observed in the subcategories of patient-oriented care before and after intervention ( $\mathrm{P}=0.040$ ) (Yeom et al. 2017). Noh et al. (2013) in South Korea in a study entitled the "moral distress, moral sensitivity and ethical climate of nurses working in psychiatric wards" also used Han et al. (2010) questionnaire. The mean score of nurses' moral sensitivity was 4.67, which was roughly average (4) and was consistent with the present study results.

The results of the study by Park et al. (2012) in South Korea, entitled "the effect of ethics education on the moral sensitivity of nursing students", showed that the inclusion of ethical education in the curriculum plays an important role in the promotion of moral sensitivity of nursing students. The results of the study by Lee et al. (2017) in Taiwan, entitled "evaluating the effect of three educational strategies on the moral sensitivity of nursing students", showed the effect of training on moral sensitivity. The tool used in this study was a modified Lützén and Comrie moral sensitivity questionnaire for nursing students.

The results of a study in Turkey, entitled "effect of ethics training on students recognizing ethical violations and developing moral sensitivity", showed that the overall scores of moral sensitivity and its subscales increased in the intervention group. The tool used in this research was Moral Sensitivity Questionnaire by Kim Lützén (Baykara et al. 2015).

A study, entitled "Evaluation of the impact of teaching nursing ethics on nurses' decision making in Kerman social welfare hospitals in 2010" showed that despite the differences in the research community and duration of the study the training was effective on the promotion of the moral sensitivity score. The instrument used in this research was Moral Sensitivity Questionnaire by Kim Lützén (Hasanpour et al. 2012).

The results of a study entitled "the effect of workshop and follow up on ethical sensitivity of nurses", showed the effect of training on moral sensitivity. All dimensions of moral sensitivity increased after the workshop and follow up in the intervention group. The tool used in this study and the overall results were the same as those of the current study (Borhani et al. 2012).

Lutzen believed that moral sensitivity is the ability of being aware of a moral conflict that does not only consist of emotions, but self-awareness of personal responsibilities in sensitive ethical situations. Gastmans stated that the inner core is the characteristics that a nurse should have, in caring for patients in need of healthcare services. However, nursing students have fewer levels of moral sensitivity than nurses (Yeom et al. 2017)

Moral sensitivity is the immediate perception of a patient's vulnerability and awareness of the meanings and concepts of the ethical implications of decisions made on his behalf. Promoting moral sensitivity during nursing education is possible. The work of nurses in health care settings is faced with situations that require ethical issues. Therefore, the need to prepare nursing students to face the ethical challenges in their future role as a nurse is highly felt (Tuvesson \& Lützén 2017).

Nursing ethics education is a training course for nursing students (Lee et al. 2017) that can play an important role in promoting the moral sensitivity of nursing students (Park et al. 2012) and change students' awareness of the possible ethical conflicts that occur during clinical education (Macale et al. 2015). According to Tuvesson \& Lützén (2017), future studies should continue to investigate the ethical sensitivity of nursing students.

Many studies show that training increases ethical sensitivity (Yeom et al. 2017; Lee et al. 2017; Park et al. 2012; Hasanpour et al. 2012; Borhani et al. 2012). Just in some studies such as that of Yeom et al. (2017) no significant changes were observed in total sensitivity score before and after training. However, some significant changes were observed in the subscales of patient centered care before and after the intervention $(\mathrm{P}=0.040)$.

The findings of various studies indicated the effectiveness of educational interventions on the moral sensitivity of different groups of society. It seems that the nature of moral sensitivity due to its extreme impressionability, growing capability, and flourish such as people's 
talents leads to the effectiveness of the training. Nursing students, as future nurses, can be effective in various aspects of health including physical, mental, social, and spiritual dimensions; providing spiritual needs by them increases the satisfaction of the patients.

It is suggested that similar studies be conducted on the relationship between demographic variables with the moral sensitivity of nursing students and other medical students and also investigating the effect of different methods of training such as workshops and seminars on the moral sensitivity of nursing students.

\section{Ethical Considerations}

\section{Compliance with ethical guidelines}

This study was approved by the Ethics Committee of IUMS (code: IR.IUMS.FMD.REC.1396.9311690001). The current study was registered at the Iranian Registry of Clinical Trials (IRCT) (Registration Code Number: $20180712040440 \mathrm{~N} 1$ ). All the students signed the informed consent.

\section{Funding}

The current study was part of a MSc. thesis of Fatemeh Ekramifar in the Department of Community Health Nursing, School of Nursing and Midwifery of IUMS

\section{Authors' contributions}

Conceptualization: Fatemeh Ekramifar, Marhamat Farahaninia, Marjan Mardani Hamooleh; Methodology: Fatemeh Ekramifar, Marhamat Farahaninia, Hamid Haghani; Investigation: Fatemeh Ekramifar; Writing-original draft: Fatemeh Ekramifar, Marhamat Farahaninia; Writing review and editing: Fatemeh Ekramifar, Marhamat Farahaninia; and Supervision: Marhamat Farahaninia.

\section{Conflict of interest}

The authors declared no conflict of interest.

\section{Acknowledgments}

The authors have appreciation for the Faculty of Nursing and Midwifery, Vice-Chancellor for Research of IUMS, students involved in the study, and library staff.

\section{References}

Abbaszadeh, A., Borhani, F. \& Abbasi, M., 2015. [Spiritual health: A model for use in nursing (Persian)]. Medical Ethics, 8(30), pp. 57-76.

Abbaszadeh, A., Borhani, F. \& Moazen-nematollahi, L., 2010. [Nurses and nursing students' moral sensitivity in Kerman Medical University in 2010 (Persian)]. Medical Ethics, 4(12), pp. 39-54.

Baloochi Beydokhti, T., et al., 2014. [Relationship between religious orientation and moral sensitivity in the decision making process among nurses (Persian)]. Iranian Journal of Medical Eth$i c s$ and History of Medicine, 7(3), pp. 48-57.

Baykara, Z. G., Demir, S.G. \& Yaman, S., 2015. The effect of ethics training on students recognizing ethical violations and developing moral sensitivity. Nursing Ethics, 22(6), pp. 661-75. [DOI:10.1177/0969733014542673]

Bolhari, J., et al., 2013. Spiritual skills: A special book of coaches. Tehran: Tehran University Consultation Center.

Borhani, F., Abbaszadeh, A. \& Mohsenpour, M., 2013, [Explaining the meaning of moral sensitivity in nursing students: A qualitative study (Persian)]. Journal of Medical Ethics, 6(22), pp. 93-115.

Borhani, F., et al., 2012. [The effect of workshop and follow-up on ethical sensitivity of nurses (Persian)]. Journal of Medical Ethics, 6(21), pp. 11-24.

Borhani, F., Keshtgar, M. \& Abbaszadeh, A., 2015. Moral selfconcept and moral sensitivity in Iranian nurses. Journal of Medical Ethics and History of Medicine, 8, p. 4. [PMID] [PMCID]

Elzadi, A., Khademi, Z. \& Asadi Noughabi, F., 2013, [The correlation of moral sensitivity of critical care nurses with their caring behavior (Persian)]. Iranian Journal of Medical Ethics, 6(2), pp. 43-56.

Galavandi, H 2016. [Predicting work ethics based on the spirituality in the workplace (Persian)]. Ethics in Science and Technology, 11(1), pp. 75-84.

Habibzade, H, Ahmadi, F \& Vanaki, Z 2010, [Ethics in professional nursing in Iran (Persian)]. Iranian Journal of Medical Eth$i c s$ and History of Medicine, 3(5), pp. 26-36.

Han, S. S, et al., 2010. Validation of a Korean version of the moral sensitivity questionnaire. Nursing Ethics, 17(1), pp. 99-105. [DOI:10.1177/0969733009349993]

Hasanpour, M., et al., 2012, [Evaluation of nursing ethics principles education on decision making in nurses who is working in Kerman social security organization hospitals (Persian)]. Iranian Journal of Medical Ethics and History of Medicine, 4(5), pp. $58-64$.

Huang, F. F., et al., 2016. Cross-cultural validation of the moral sensitivity questionnaire-revised Chinese version. Nursing Ethics, 23(7), pp. 784-93. [DOI:10.1177/0969733015583183]

Khodabakhshi, S., Rahimi kia, A., \& Jafari, H. 2014. [Identifying the relationship between spiritual intelligence and mental health of students of Lorestan University of Medical Sciences (Persian)]. Quarterly Journal of Lorestan University of Medical Sciences, 16(1), pp. 58-65.

Kim, Y. S, Kang, S. W., \& Ahn, J. A., 2013. Moral sensitivity relating to the application of the code of ethics. Nursing Ethics, 20(4), pp. 470-8. [DOI:10.1177/0969733012455563] 
Lee, H. L., Huang, S. H. \& Huang, C. M., 2017. Evaluating the effect of three teaching strategies on student nurses' moral sensitivity. Nursing Ethics, 24(6), pp. 732-43. [DOI:10.1177/0969733015623095]

Lützen, K., et al., 2010. Moral stress, moral climate and moral sensitivity among psychiatric professionals. Nursing Ethics, 17(2), pp. 213-24.[DOI:10.1177/0969733009351951]

Lützén, K., Nordin, C. \& Brolin, G., 1994. Conceptualization and instrumentation of nurses' moral sensitivity in psychiatric practice. International Journal of Methods in Psychiatric Research, 4(4), pp. 241-8. [DOI:10.1037/t60329-000]

Macale, L., et al., 2015. Development of the ethical sensitivity scale in undergraduate nursing students. Professioni Infermieristiche, 68(4), pp. 244-50. [DOI:10.7429/pi.2015.684244]

Nikjoo, A., et al., 2014, [The correlation between moral sensitivity with tendency to leave work in nurses (Persian)]. Education E Ethic In Nursing, 3(4), pp. 25-32.

Noh, D., Kim, S. \& Kim, S., 2013. Moral distress, moral sensitivity and ethical climate of nurses working in psychiatric wards Journal of Korean Academy of Psychiatric and Mental Health Nursing, 22(4), pp. 307-19. [DOI:10.12934/jkpmhn.2013.22.4.307]

Park, M., et al., 2012. The relationship of ethics education to moral sensitivity and moral reasoning skills of nursing students. Nursing Ethics, 19(4), pp. 568-80. [DOI:10.1177/0969733011433922]

Tuvesson, H. \& Lützén, K., 2017. Demographic factors associated with moral sensitivity among nursing students. Nursing Ethics, 24(7), pp. 847-55. [DOI:10.1177/0969733015626602]

Yeom, H. A., Ahn, S. H. \&Kim, S. J., 2017. Effects of ethics education on moral sensitivity of nursing students. Nursing Ethics, 24(6), pp. 644-52. [DOI:10.1177/0969733015622060] 
This Page Intentionally Left Blank 